\title{
Validation of Airborne FMCW Radar Measurements of Snow Thickness Over Sea Ice in Antarctica
}

\author{
Natalia Galin, Anthony Worby, Thorsten Markus, Carl Leuschen, and Prasad Gogineni, Fellow, IEEE
}

\begin{abstract}
Antarctic sea ice and its snow cover are integral components of the global climate system, yet many aspects of their vertical dimensions are poorly understood, making their representation in global climate models poor. Remote sensing is the key to monitoring the dynamic nature of sea ice and its snow cover. Reliable and accurate snow thickness data are currently a highly sought after data product. Remotely sensed snow thickness measurements can provide an indication of precipitation levels, predicted to increase with effects of climate change in the polar regions. Airborne techniques provide a means for regional-scale estimation of snow depth and distribution. Accurate regional-scale snow thickness data will also facilitate an increase in the accuracy of sea ice thickness retrieval from satellite altimeter freeboard estimates. The airborne data sets are easier to validate with in situ measurements and are better suited to validating satellite algorithms when compared with in situ techniques. This is primarily due to two factors: better chance of getting coincident in situ and airborne data sets and the tractability of comparison between an in situ data set and the airborne data set averaged over the footprint of the antennas. A 2-8-GHz frequency modulated continuous wave (FMCW) radar loaned by the Center for Remote Sensing of Ice Sheets to the Australian Antarctic Division is used to measure snow thickness over sea ice in East Antarctica. Provided with the radar design parameters, the expected performance parameters of the radar are summarized. The necessary conditions for unambiguous identification of the air/snow and snow/ice layers for the radar are presented. Roughnesses of the snow and ice surfaces are found to be dominant determinants in the effectiveness of layer identification for this radar. Finally, this paper presents the first in situ validated snow thickness estimates over sea ice in Antarctica derived from an FMCW radar on a helicopterborne platform.
\end{abstract}

Index Terms-Airborne, Antarctica, frequency modulated continuous wave (FMCW), sea ice, snow.

\section{INTRODUCTION}

$\mathbf{T}$ HE POLAR regions play a key role in the Earth's climate system, considered amplifiers of climate events, be they

Manuscript received May 27, 2010; revised December 14, 2010 and March 20, 2011; accepted May 1, 2011. Date of publication July 12, 2011; date of current version December 23, 2011.

N. Galin is with the Centre for Polar Observation and Modelling, University College London, WC1E 6BT London, U.K (e-mail: n.galin@ucl.ac.uk).

A. Worby is with the Australian Antarctic Division, Kingston, Tas. 7050, Australia (e-mail: A.Worby@utas.edu.au).

T. Markus is with the Cryospheric Sciences Branch, Hydrospheric and Biospheric Sciences Laboratory, Goddard Space Flight Center, National Aeronautics and Space Administration, Greenbelt, MD 20771 USA (e-mail: thorsten.markus@nasa.gov).

C. Leuschen and P. Gogineni are with the University of Kansas, Lawrence, KS 66045-7621 USA (e-mail: leuschen@eecs.ku.edu; gogineni@ cresis.ku.edu).

Color versions of one or more of the figures in this paper are available online at http://ieeexplore.ieee.org.

Digital Object Identifier 10.1109/TGRS.2011.2159121 natural or anthropogenic. It is generally considered that changes in the climate will be most pronounced at these two remote parts of our planet [1]. The sensitivity of the poles is mainly due to the presence of sea ice, and its importance is recognized in its inclusion as one of the three key components in climate models: ocean-sea ice-atmosphere [2]. In addition, sea ice has a major impact on the Earth's heat budget, ocean-atmosphere interaction, and ocean circulation.

The addition of snow to the surface of sea ice compounds many of the climate and biological processes that sea ice influences. Having an even higher albedo and lower thermal conductivity than sea ice [3], snow increases the reflection of solar radiation back into space and strongly affects ocean-ice-atmosphere heat exchange. Consequently, snow cover can drastically retard the growth of sea ice in winter and delay melt in summer time [4].

In order to understand the effects and feedback mechanisms of the changing climate on the extent and thickness of sea ice and its snow cover and their seasonal variability, it is imperative to globally monitor ice and snow properties on a continuous basis. Only satellite remote sensing can provide this information. A number of methods have already been developed to measure sea ice elevation and freeboard of sea ice using either laser [5], [6] or radar satellite altimetry [7] data which are then used to estimate the total sea ice thickness. Knowledge of snow cover is recognized as critical to extracting accurate ice thickness from altimeter data.

Other than model output, climatologies, and the extensive compilation of ship-based observations in Antarctica [8], the only existing large-scale snow depth product comes from the passive AMSR-E instrument on National Aeronautics and Space Administration's Aqua satellite [9], [10], but recent studies have shown problems, particularly over rough sea ice [11]. Worby et al. [12] and Massom et al. [13] describe results from an extensive set of experiments conducted during a voyage into the East Antarctic zone in 2003 to validate satellite sea ice data products. It was found that AMSR-E significantly underestimates the snow thickness and its performance is dramatically affected by the roughness of the underlying sea ice.

Large-scale satellite data are hard to validate satisfactorily with in situ data considering that not only it is difficult to achieve coincident measurements with satellite overpasses but also the methodology of combining the large pixel size averages (the order of tens of meters, for example) of a highly heterogeneous snow cover distribution to that of a single in situ (centimeter-size pixel) measurement is unknown. To address this drawback, research has been directed to the development of sled (average pixel sizes of meters) and/or airborne (average 
pixels sizes of tens of meters) remote sensing investigation techniques which are themselves easier to validate with in situ data and are capable of covering a large area which, in turn, can then be used for validating satellite data.

A strong case for the use of radar, together with laser, altimetry for snow thickness extraction is provided in [14]. However, using separate radar and laser systems requires precise calibration of the instruments and compensation of footprint differences. Ultrawideband frequency modulated continuous wave (FMCW) radars are able to extract both the air/snow and snow/ice interfaces simultaneously and have been used extensively for snow depth studies [15]. They provide the ideal means for medium-scale nondisruptive estimates of snow cover. However, only a few have been airborne, and even fewer have been employed for research over sea ice in Antarctica.

Until now, FMCW radar operation has been conclusively demonstrated to work from a sled-based platform [16]-[18], and airborne experiments have been performed over ice sheets, lake ice, or mountain regions [19]-[22]. However, to date, results of snow thickness estimation over sea ice from airborne radar are not currently available in the published literature. The difficulty in achieving this has been the stringent requirement imposed on the FMCW radar during higher altitude operation, a problem not present in handheld or sledoperated radar. This requirement to a first order manifests itself in the linearity performance of the radar; the higher the altitude of the radar, the less tolerance there is to nonlinearities that are necessarily present in a practical system.

This paper provides the first validation effort of snow thickness retrievals from airborne FMCW radar over sea ice in Antarctica. First, a description of the radar system is provided in terms of the design and performance parameters. Based on these values, the minimum backscattering coefficient that the radar is sensitive to is presented. This allows for the limitations of the radar performance to be gauged in terms of detection sensitivity in general and sensitivity to layering within the snow pack. Provided with the performance parameters of the radar, the following section describes the necessary conditions for unambiguous identification of the air/snow and snow/ice layers. The flights and in situ collection procedures are then described, and the validation procedure is presented. Finally, error analysis is performed to characterize the confidence in snow thickness retrievals.

\section{OVERVIEW OF FMCW RADAR}

The principal idea of FMCW rests on the fact that the product of two harmonics is equivalent to the sum of two sinusoidal signals whose frequency values are the difference and sum of the two harmonics. Whereas pulse radar systems use the time between transmission and reception of the pulse for detection and ranging, in FMCW systems, the delay in time of the transmitted signal is mapped into a difference frequency, and it is the value of the difference frequency which carries the detection/ranging information. Brooker [23] provides a detailed overview of the basics of the radar design and components.

A 2-8-GHz FMCW radar was loaned by the Center for Remote Sensing of Ice Sheets to the Australian Antarctic Division
TABLE I

RADAR DESIGN PARAMETERS

\begin{tabular}{|l|l|l|l|}
\hline Description & Symbol & Value & Unit \\
\hline Operating Frequency & $\Delta f$ & $2-8$ & $\mathrm{GHz}$ \\
\hline Sweep Time & $T_{p}$ & 1.25 & $\mathrm{~ms}$ \\
\hline Sweep Type & & Triangular & Linear \\
\hline & & & $\mathrm{Continuous}$ \\
\hline Chirp Repeat Frequency & $\mathrm{CRF}$ & 400 & $\mathrm{~Hz}$ \\
\hline Transmit Power & $P_{t}$ & 30 & $\mathrm{dBm}$ \\
\hline Antenna 3dB Beamwidth & & & \\
\hline - along track & $\theta$ & $>80$ & degrees \\
\hline - across track & $\psi$ & 8 & degrees \\
\hline Antenna Gain & $G_{r x} ; G_{t x}$ & 10 & $\mathrm{dBi}$ \\
\hline Low Pass Filter & $f_{L P F}$ & 5 & $\mathrm{MHz}$ \\
\hline High Pass Filter & $f_{H P F}$ & 1 & $\mathrm{MHz}$ \\
\hline Operating Speed & & & \\
\hline - minimum & $v_{\min }$ & 20 & $\mathrm{~m} / \mathrm{s}$ \\
\hline - maximum & $v_{\max }$ & 35 & $\mathrm{~m} / \mathrm{s}$ \\
\hline Sampling Frequency & $f_{s}$ & 12.5 & $\mathrm{MHz}$ \\
\hline ADC & & 12 & $\mathrm{bits}$ \\
\hline
\end{tabular}

TABLE II

RADAR Performance Parameters

\begin{tabular}{|l|l|l|l|}
\hline Description & Symbol & Value & Unit \\
\hline Range Resolution & $\delta R$ & 37.5 & $\mathrm{~mm}$ \\
\hline Operating Range & & & \\
\hline - minimum & $R_{\min }$ & 31.25 & $\mathrm{~m}$ \\
\hline - maximum & $R_{\max }$ & 156.25 & $\mathrm{~m}$ \\
\hline Active Area & & & \\
\hline - min range & $A_{\min }$ & 7.37 & $\mathrm{~m}^{2}$ \\
\hline - max range & $A_{\max }$ & 30.6 & $\mathrm{~m}^{2}$ \\
\hline Minimum Detectable Signal & $\mathrm{MDS}$ & -138 & $\mathrm{dBm}$ \\
\hline - min range & $\sigma^{0}$ & -107 & $\mathrm{~dB}$ \\
\hline - max range & $\sigma^{0}$ & -87 & $\mathrm{~dB}$ \\
\hline
\end{tabular}

(AAD) for fitting and operation from a helicopter platform. The design parameters of the radar supplied are presented in Table I. As can be seen from the summary provided in the table, the antenna along-track beamwidth is quite large, and admittedly, this is a design shortcoming. Such a large beamwidth is essentially an inefficient use of transmitted power; however, due to the pulse limited operation of the radar, it does not affect the radar resolution performance. Due to time and logistical resource constraints, these were the only antennas certified for operation from the helicopter. In future experiments, improvement of the antennas is a first priority.

\section{A. Radar System Description}

The interpretation of the performance parameters based on the design parameters and adjustments to helicopterborne operation is summarized in Table II. Due to the almost unlimited beamwidth of the radar in the along-track dimension, the radar illuminates a large area on the ground with a transmitted chirp signal every $1.25 \mathrm{~ms}$. However, due to the nature of the postprocessing of the FMCW radar data, where a pseudomatched filtering operation takes place in the fast Fourier transform filter bank, the pixel on the ground (i.e., active area) from which all returns are integrated into a single range bin is calculated to be approximately $24 \mathrm{~m}^{2}$ (at a nominal operating altitude of $100 \mathrm{~m}$ ). Provided that the detection probability of the radar is set to 0.5 and the false-alarm rate is set at $10^{-3}$, the minimum backscattering coefficient that the radar is 


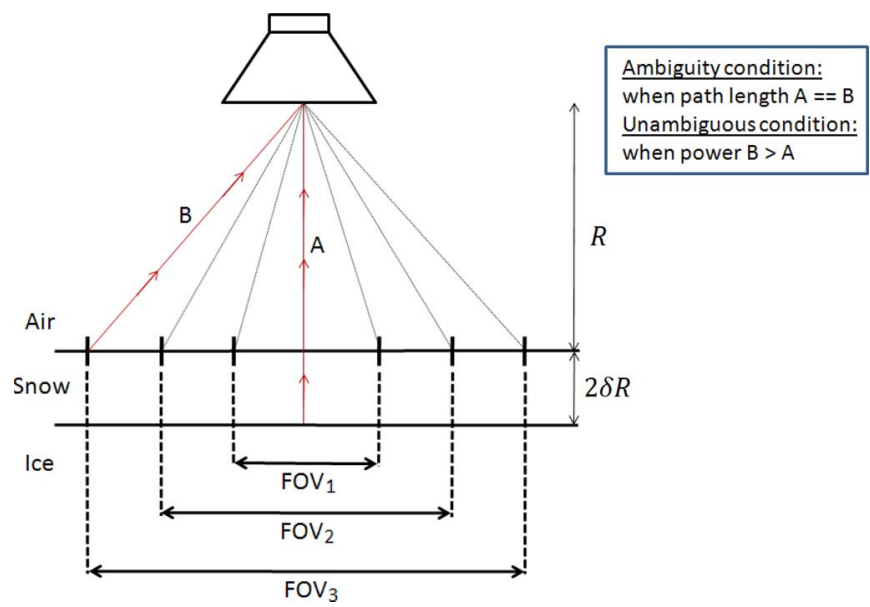

Fig. 1. Possible ambiguity condition in returns from the air/snow and snow/ice interfaces.

sensitive to is approximately $-107 \mathrm{~dB}$. The usable bandwidth of the radar enables it to unambiguously distinguish returns that are vertically spaced further than $37.5 \mathrm{~mm}$ apart. The usable bandwidth in this case was measured to be $4 \mathrm{GHz}$; hence, it follows that the vertical resolution is $(c / B W) \approx 3 \times 10^{8} /(2 \times$ $\left.4 \times 10^{9}\right)=0.0375 \mathrm{~m}$.

In the case of a smooth (low spatial frequency) surface, it would be elementary to distinguish the surface return from the subsurface. The radar in this case would be receiving close to specular reflections, and there is then no ambiguity with respect to a subsequent return arriving from a different off-nadir range cell or due to the subsurface (i.e., snow/ice interface reflection).

If the surface is rough, ambiguity in the identification of the snow/ice from the air/snow may occur. Fig. 1 shows a likely condition whereby a return from the surface air/snow interface coming from an adjacent range cell occurs in the same range bin as the return from the snow/ice interface. Due to the relatively shallow $(\approx 100 \mathrm{~mm}$ ) snow cover over Antarctic sea ice, which is also quite frequently subject to deformation and, hence, has an uneven surface, the chance of an off-angle facet may result in a shorter path delay when compared to the nadir path length. Under these circumstances, to achieve unambiguous identification of the air/snow and snow/ice interfaces, it is required that the power level of the air/snow $\left(P_{a / s}\right)$ interface be lower than that coming from the snow/ice $\left(P_{s / i}\right)$ interface

$$
P_{a / s}<P_{s / i}
$$

which is shown in Fig. 2. If this condition is not met, the return from the snow/ice interface will not be identifiable from the offnadir returns from the air/snow interface (see also [24]).

\section{Modeling The Conditions For SnOw INTERFACE IDENTIFICATION}

Provided that the refractive index is the sole parameter affecting the distribution of power between reflection and transmission of incident electromagnetic radiation at the interface of two media, the upper bound on the reflected power from the air/snow and snow/ice interfaces can be derived. Referring to

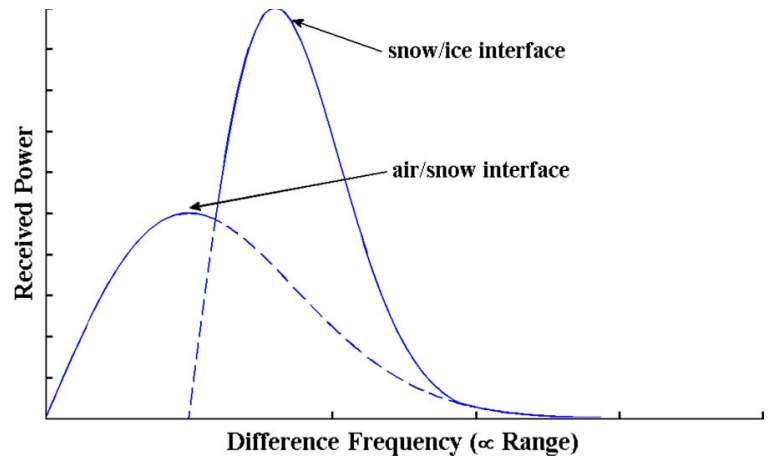

Fig. 2. Return power requirements for the air/snow and snow/ice interfaces for unambiguous identification.

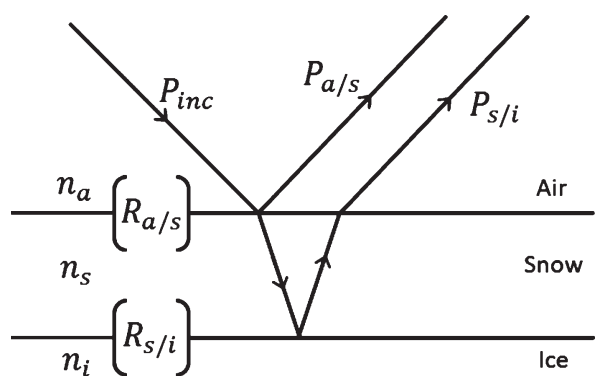

Fig. 3. Reflection and refraction/transmission at air/snow and snow/ice interfaces.

Fig. 3, the reflected powers at the air/snow interface $\left(P_{a / s}\right)$ and the snow/ice interface $\left(P_{s / i}\right)$ are expressed as

$$
\begin{aligned}
& P_{s / a}=\left(R_{a / s}\right)^{2} P_{\mathrm{inc}} \\
& P_{s / i}=\left(1-R_{a / s}^{2}\right) P_{\mathrm{inc}} R_{s / i}^{2}\left(1-R_{a / s}^{2}\right)
\end{aligned}
$$

where $P_{\text {inc }}$ is the power incident at the air/snow interface and $R_{a / s}$ and $R_{s / i}$ are the Fresnel reflection coefficients (at nadir incidence) at the air/snow and snow/ice interfaces, respectively. Using (1) and substituting for $P_{s / a}$ and $P_{s / i}$ from (2) and (3), the condition for unambiguous identification of the return from the snow/ice interface becomes

$$
R_{a / s}^{2} P_{\mathrm{inc}}<\left(1-R_{a / s}^{2}\right) P_{\mathrm{inc}} R_{s / i}^{2}\left(1-R_{a / s}^{2}\right)
$$

or

$$
R_{a / s}^{2} P_{\mathrm{inc}}=K\left(1-R_{a / s}^{2}\right) P_{\mathrm{inc}} R_{s / i}^{2}\left(1-R_{a / s}^{2}\right)
$$

where $K$ is the relative power factor, introduced here to model the degree to which the power is divided at the interfaces. Provided that $K<1$, this relationship summarizes the conditions necessary for unambiguous identification of the interfaces.

Quantifying this relationship allows for an assessment of the likelihood of this condition to be satisfied. The refractive index of air is conventionally equal to unity, and the literature [25][27], [29] summarizes the range of likely values for $n_{s}$ (snow) and $n_{i}$ (sea ice) to be

$$
\begin{aligned}
& n_{s}: 1.2 \rightarrow 2.0 \\
& n_{i}: 3.1 \rightarrow 3.5 .
\end{aligned}
$$




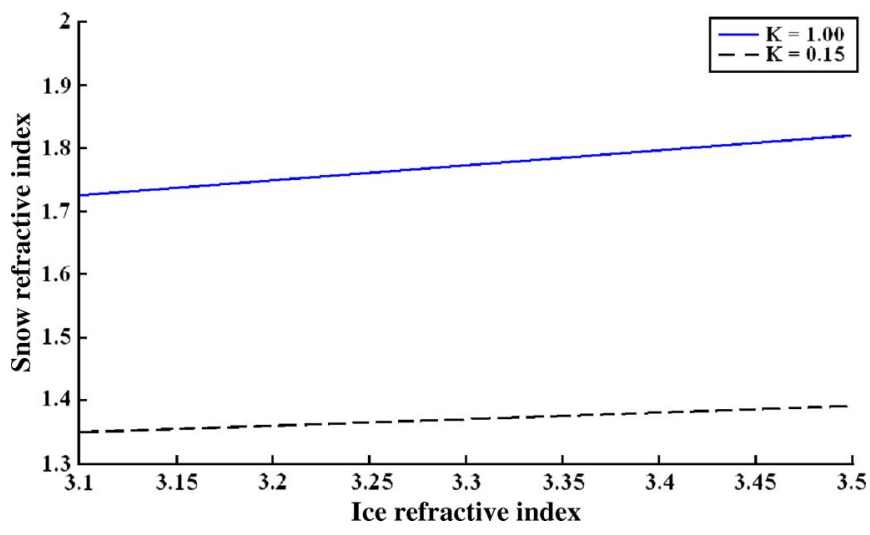

Fig. 4. Snow refractive index as a function of ice refractive index required to satisfy unambiguous relative power requirements.

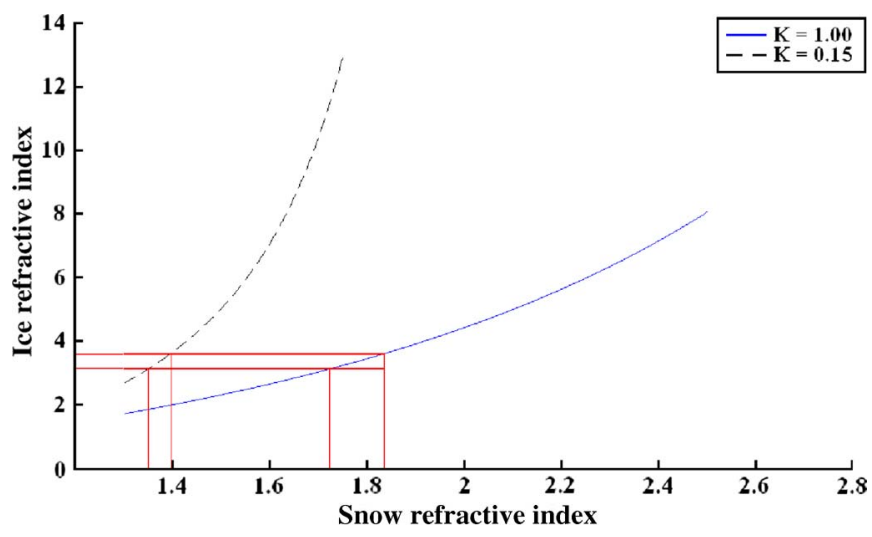

Fig. 5. Ice refractive index as a function of snow refractive index required to satisfy unambiguous relative power requirements.

Considering the model conditions of $K=1.0$ and $K=0.15$ which examine the case when the power returns from the air/snow and snow/ice interfaces are equal and when there is approximately an 8-dB difference, Fig. 4 shows the range of the refractive index of snow given the range of the refractive index of ice that satisfies these conditions. The results in the figure indicate that it is not unrealistic to assume a higher power return from the snow/ice interface compared to the return from the air/snow interface. However, it should be noted that this model also exposes the high sensitivity to small changes in the refractive index of snow, a small change which can necessitate an unrealistically high refractive index for ice to maintain unambiguous detection ability, shown in Fig. 5. Furthermore, the two figures together provide a picture of the range of the refractive index for snow which will allow the underlying sea ice to be detected by the radar. Admittedly, these calculations are only applicable under dry snow conditions. If the snow is wet, attenuation of the signal may limit or prevent signal penetration and reflection. In cases of flooding of the sea ice, its reflection coefficient will increase; however, subsequent and likely wicking of the salty brine into the snow cover could prevent penetration of the radar signal into the snow cover completely.

\section{A. Backscattering Coefficient Estimation}

The previous section considered the upper bound on the power distribution between the air/snow and snow/ice in- terfaces assuming smooth surface conditions. However, this is unlikely to be the case for sea ice and its snow cover, and it is the surface backscattering coefficient which is the most appropriate for capturing the amount of reflected power from these rough surfaces. The generally quoted empirical model for the backscattering coefficient of snow covered ice is [25]

$$
\sigma^{0}(\theta)=\sigma_{a / s}^{0}(\theta)+T_{a / s}^{2}(\theta)\left[\sigma_{\mathrm{sv}}^{0}\left(\theta^{\prime}\right)+\frac{1}{L^{2}\left(\theta^{\prime}\right)} \cdot \sigma_{s / i}^{0}\left(\theta^{\prime}\right)\right]
$$

with ice volume scattering neglected and where $\sigma_{a / s}^{0}(\theta)$ is the backscattering coefficient for the snow surface, i.e., the air/snow interface, $\sigma_{\mathrm{sv}}^{0}\left(\theta^{\prime}\right)$ is the backscattering coefficient for the snow volume, $\sigma_{s / i}^{0}\left(\theta^{\prime}\right)$ is the backscattering coefficient for the ice surface, i.e., the snow/ice interface, $T_{a / s}(\theta)$ is the Fresnel transmission coefficient at the air/snow interface, $L\left(\theta^{\prime}\right)$ is the one-way propagation loss through the snow, $\theta$ is the incidence angle, and $\theta^{\prime}$ is the refraction angle in the snow. In the aforementioned equation, signal attenuation in the snow pack is neglected, and only the dry snow case is considered.

However, the aforementioned equation aggregates the surface and volume scattering contributions into a single backscattering component and represents the total backscattered power that is received at the radar over the whole chirp duration. This radar, however, is sensitive to the time delay of the backscatter during the chirp. Incorporating this time dependence, the backscattering coefficient is rewritten as

$$
\sigma^{0}(\theta, \tau)= \begin{cases}\sigma_{a / s}^{0}, & \tau 1 \leq t<T_{p}-\tau_{1} \\ \sum_{\tau=\tau_{1}}^{\tau_{3}} T_{a / s}^{2}\left(\theta, \tau_{\mathrm{sv}}\right)\left[\sigma_{\mathrm{sv}}^{0}\left(\tau_{\mathrm{sv}}\right)\right], & \tau_{1} \leq t<T_{p}-\tau_{3} \\ T_{a / s}^{2}(\theta)\left[\sigma_{s / i}^{0}\left(\theta^{\prime}\right)\right], & \tau_{3} \leq t<T_{p}-\tau_{3}\end{cases}
$$

where $t$ varies over the chirp duration $0<t<T_{p}, \tau_{1}$ corresponds to the delay in the signal due to the separation between the radar and air/snow interface, $\tau_{\mathrm{sv}}$ corresponds to the delay in the signal due to volume scattering events (that can occur anywhere between $\tau_{1}$ and $\tau_{3}$, as is indicated by the sum), and $\tau_{3}$ corresponds to the delay in the signal due to the separation between the radar and ice/snow interface (incorporating the change in propagation velocity).

The purpose of the radar is to find the snow thickness and thereby find the time separation between the air/snow interface component $\left(\sigma_{a / s}^{0}\right)$ and the snow/ice interface component $\left(\sigma_{s / i}^{0}\right)$. As previously demonstrated, for unambiguous detection of the air/snow and snow/ice interfaces, it is imperative that the snow/ice interface has a higher backscattering component relative to the air/snow interface.

In the sections to follow, the roughness conditions of the air/snow and snow/ice interfaces will be found, and the approximate backscattering coefficient for the two interfaces will be calculated, demonstrating that the radar under the presented experimental conditions was indeed able to unambiguously identify the air/snow and snow/ice interfaces. 


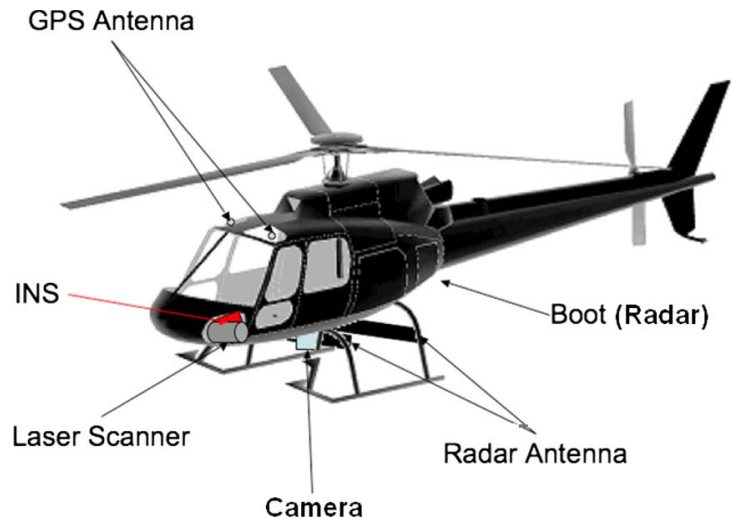

Fig. 6. Schematic of the Radar-Aeiral Photography-Pyrometer-Laser Scanner helicopter instrument arrangement. Courtesy of J. Lieser.

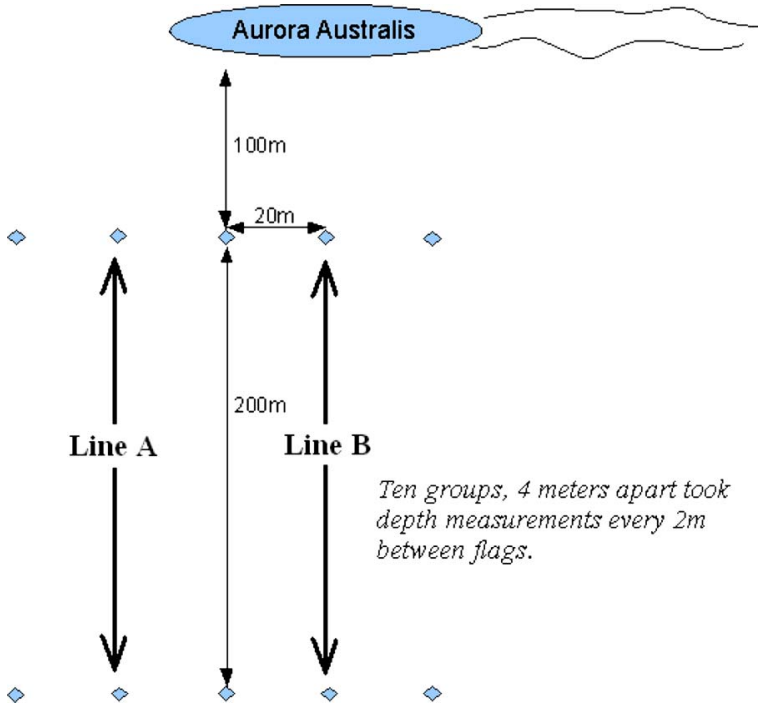

Fig. 7. Schematic of the area near the ship where in situ and flight experiments were performed.

\section{EXPERIMENTAL SETUP}

The radar, together with a laser altimeter differential inertial navigation system and a camera, was installed into an instrumentation helicopter operated by the AAD. Fig. 6 shows a schematic of the helicopter (Eurocopter AS-350 BA "Squirrel"), illustrating the location of the equipment. The addition of a laser and a digital camera to the radar data allows for a multifaceted survey of the surface conditions to be made. The helicopter was taken on board the first voyage of the 2008 Aurora Australis RSV resupply during the 2008 season to East Antarctica, visiting the Australian Antarctic Station Davis, situated $68^{\circ} 35^{\prime} \mathrm{S}, 77^{\circ} 58^{\prime} \mathrm{E}$. Only $24 \mathrm{~h}$ was allocated to science during the voyage, and flights were planned over the pack ice as the ship approached the Davis Station. However, due to logistical difficulties, flight time was only available once we had approached the fast-ice zone.

Experimental flights conducted with the helicopterborne radar were made over a marked out area of $200 \mathrm{~m} \times 80 \mathrm{~m}$, approximately $100 \mathrm{~m}$ away from the ship. In situ snow thickness measurements were taken every $2 \mathrm{~m}$, snow temperature every $10 \mathrm{~m}$, and snow density every $20 \mathrm{~m}$. Fig. 7 shows a basic

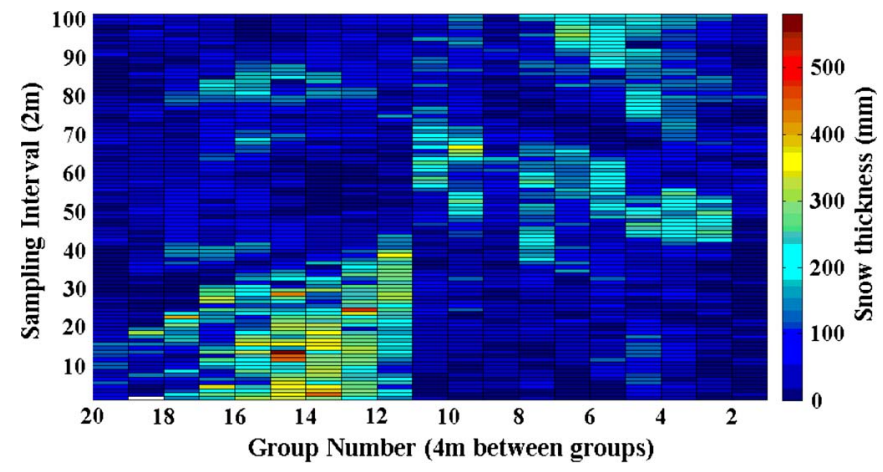

Fig. 8. In situ measured snow depth distribution map of the experimental area.

schematic of the marked area indicating the flight lines (A and B), and below that (Fig. 8) is a map of the recorded snow depth in millimeters. The average air temperature recorded across this area is $-10{ }^{\circ} \mathrm{C}$; consequently, it is assumed that the snow pack has low moisture [30].

\section{A. Experimental Description}

The radar was flown over the lines marked $\mathrm{A}$ and $\mathrm{B}$, at two different altitudes, and three times over at each altitude. This was done in order to minimize the possibility that the extracted snow thickness samples from the radar data were corrupted by biases, due to systematic and/or otherwise random error in the data, and any postprocessing algorithms. The data presented here will be for flight line A where the maximal variability in snow thickness is measured by the in situ results. This is for the reason that the snow variability is quite small (maximum of $300 \mathrm{~mm}$ ), which indicates, at most, an eight-range-bin distribution, and in line B, there is no clear snow thickness pattern as that present in line A. The comparison between 50- and $100-\mathrm{m}$ altitudes is made to gauge the relative contribution of possible (probable) errors in the helicopter operation (such as off-nadir pointing, off-track flight line, and vibration), as well as to make a comparison between the contributions of the different roughness scales of the snow and ice surfaces.

An estimate of the roughness conditions of the overflown surfaces is provided by the laser altimeter. The laser range measurements are used for approximating the average standard deviation of the surface height at the operating altitudes of 50 and $100 \mathrm{~m}$. At these altitudes, the laser spot sizes are 0.23 and $0.06 \mathrm{~m}^{2}$, respectively; consequently, the returns are considered point measurements of the surface height. The difficulty with the laser sampling of the surface is that, due to the variation in speed of the helicopter, the spatial frequency (distance) of sampling is not constant-consequently, it is not possible to directly retrieve the correlation length. However, calculating the standard deviation of the surface height across increasing distances (as shown in Fig. 9) allows for an indirect/first-order measure of the correlation length of the surface to be estimated. The reason that the altitude must be specified in deriving the standard deviation values is that the active area of the radar at these altitudes undersamples the surface roughness of the snow. This fact is also shown in Fig. 9, where the helicopter operating altitude places the active area of the radar at the changing slope 


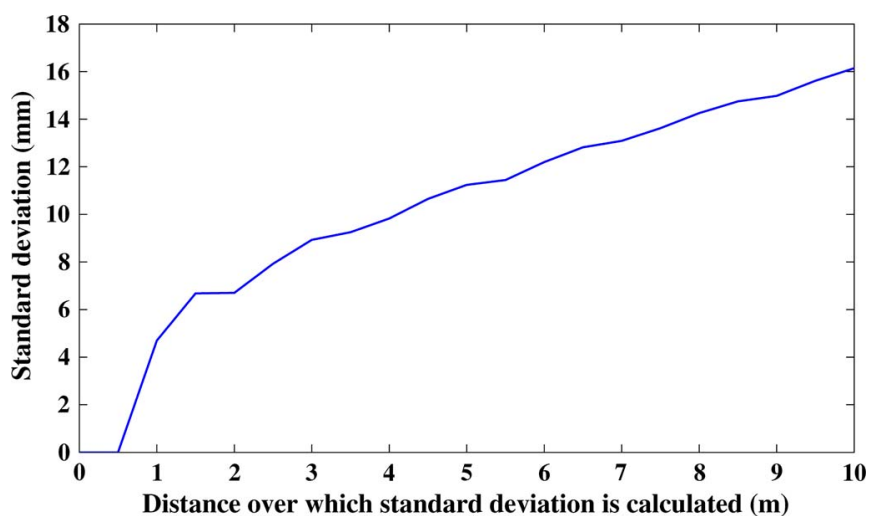

Fig. 9. Fast-ice experimentally derived standard deviation values of surface roughness.

of the curve. Using this figure, the average expected standard deviation is found to be 9.5 and $10.5 \mathrm{~mm}$ for the 50 - and $100-\mathrm{m}$ operating altitudes, respectively.

These values are used to approximate the backscattering coefficient based on the surface roughness parameters [28], [29]

$$
\sigma^{0}=|R|^{2} e^{(-2 g)}
$$

where $g$ is known as the specular reflection coefficient reduction factor and given in [28] as

$$
\sqrt{g} \equiv 2 \pi \frac{\sigma}{\lambda}
$$

where $\sigma$ is the standard deviation of surface height and $\lambda$ is the wavelength of the employed radiation. From this approximation for the backscattering coefficient, it is likely that roughness properties of the air/snow and snow/ice interfaces will play a significant role in the ability of the radar (particularly at the wavelengths used, i.e., $50-150 \mathrm{~mm}$, due to the fact that they are comparable with the roughness features themselves) to unambiguously detect air/snow and snow/ice interfaces.

Fortunately, it can be asserted that, under similar roughness conditions, the interface with the greatest dielectric contrast will lead to greater degree of scattering [31], [32]. Consequently, the condition for the air/snow interface to have a lower power return than the snow/ice interface is not unrealistic. Provided that the flights were conducted over the fast-ice zone, it was considered appropriate to specify the roughness of the snow/ice interface as less than that recorded for the air/snow interface. Fig. 10 shows the approximate expected backscatter coefficient for the air/snow and snow/ice interfaces, demonstrating that it is likely that the snow/ice backscatter is greater than the air/snow backscatter.

Three flights for the line at the 50-m altitude and three flights at the 100-m altitude were identified as the flights suitable for validation purposes. Fig. 11 shows the raw radar echogram for a flight at the 50-m altitude, approximately over the in situ sampled area. It is very difficult to identify the air/snow and snow/ice reflection lines with fine resolution. The cause of this has been identified to be the frequency generator which produces the 2-8-GHz sweep and is a common cause of problem in wideband FMCW radar [33]. Fortunately, this also means that the error is mostly systematic in nature and, consequently,

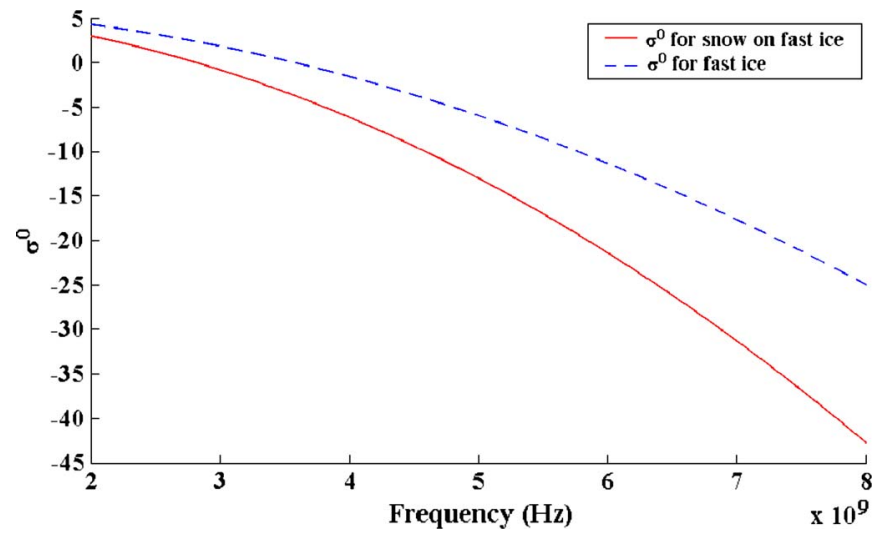

Fig. 10. Calculated $\sigma^{0}$ for fast ice.

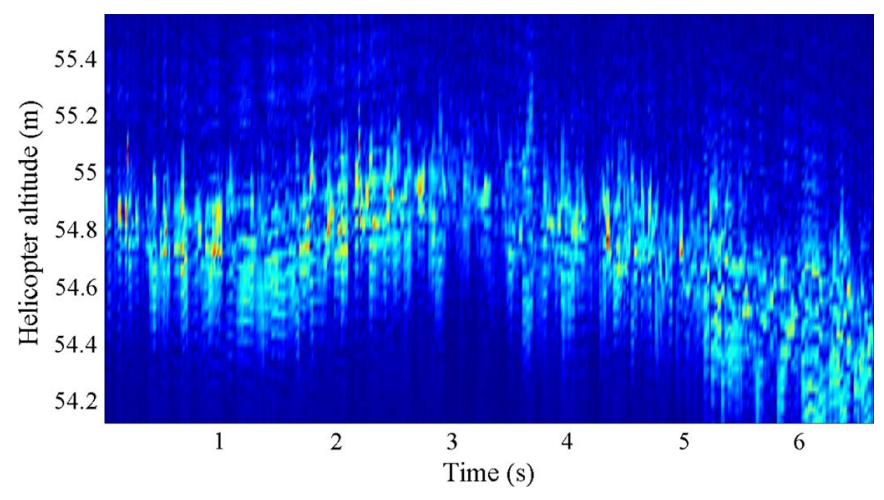

Fig. 11. Echogram of raw radar data collected over the in situ studied area.

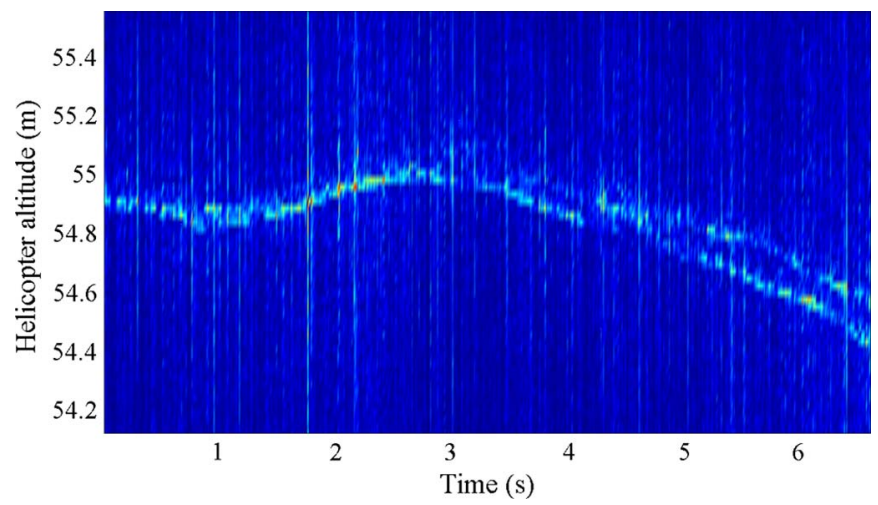

Fig. 12. Echogram of radar data over in situ studied area after application of linearizing algorithm.

can be inverted. The principle behind the algorithm written to undo the effects of the nonlinearities is to use the phase history of a fixed target (a copper coaxial delay line) inserted into the system between the transmit and receive paths to linearize the phase history of the received reflections from the unknown targets. Meta et al. [34] and Vossiek et al. [35] describe similar nonlinearity correcting algorithms for FMCW radar. The main point to note is that the nonlinearities are systematic and their effect is range dependent; consequently, the same radar may work from a sled platform when the range between the transmit and receive antennas is less than $2 \mathrm{~m}$ but fail to work from a helicopter platform when the range to the target exceeds $50 \mathrm{~m}$. Fig. 12 shows the same radar data after application of a linearizing algorithm. 


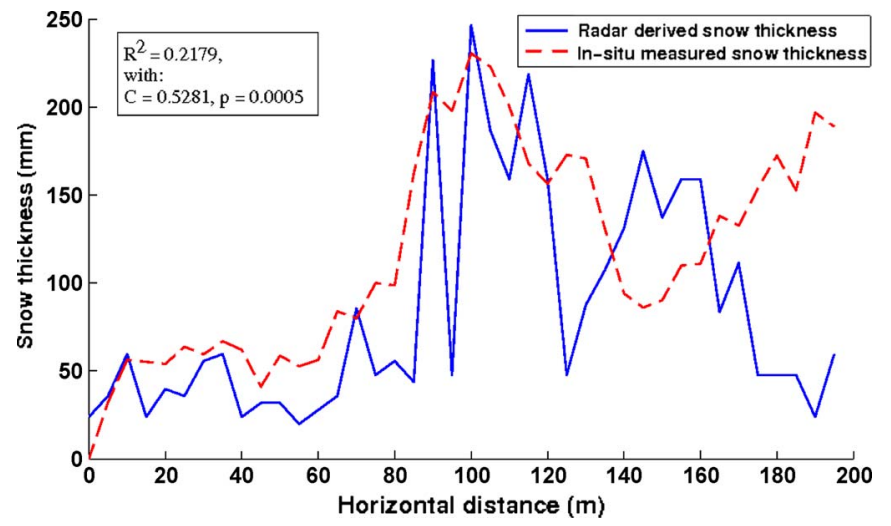

Fig. 13. In situ and radar data comparison, for three passes at 50-m altitude. Plotted as a function of distance along the 200-m transect.

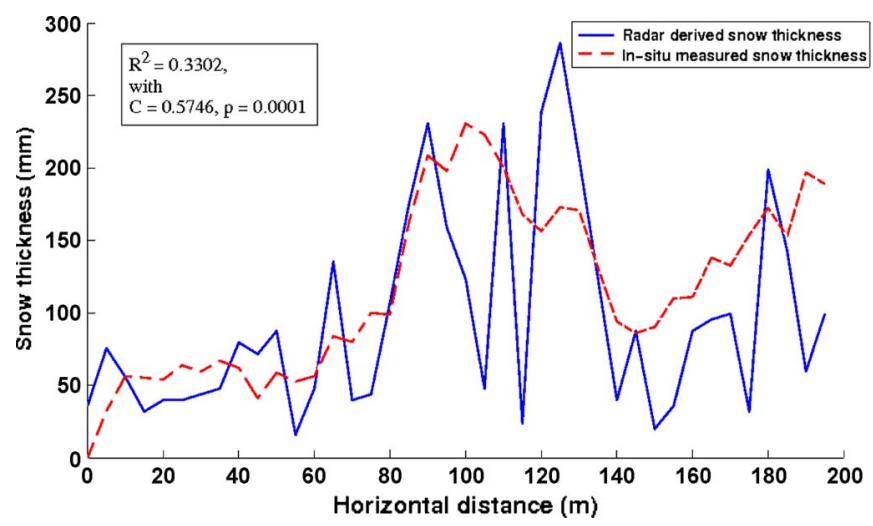

Fig. 14. In situ and radar data comparison, for three passes at 100-m altitude. Plotted as a function of distance along the 200-m transect.

To extract the air/snow and snow/ice data, a simple automatic peak picking algorithm is applied. The first peak is found as the one of largest amplitude, and then, localization of the second is made to the left of the first one, no less than $10 \mathrm{~dB}$ below in amplitude [36]. Then, a condition is applied that the peak must remain in the same location for as long as the radar footprint is sampling a similar surface. In this particular case, this condition leads to the expectation that the peaks will maintain the same location for three consecutive radar returns. The radar travel time thus derived is converted into snow depth using an average snow density of $300 \mathrm{~kg} / \mathrm{m}^{3}$. This was justified by studies which showed that, with a shallow snow pack, a large error in density can be tolerated without the radar return moving by a range bin.

\section{Results}

Figs. 13 and 14 show a comparison of the averaged snow thickness values over the three passes for 50 and $100 \mathrm{~m}$, with the in situ values over the 200-m transect. (Figs. 15 and 16 show the temperature and density profiles measured over the line.) The substantial deviation between the in situ results and the radar data for the 50-m altitude returns from $120 \mathrm{~m}$ onward to the end of the 200-m transect may be a product of geolocation error, due to the fact that this is present in all of the three passes. Additionally, it is interesting to observe the consistent presence of three peaks in both figures in the middle section of the transect at approximately 90 and $130 \mathrm{~m}$. Correspondingly,

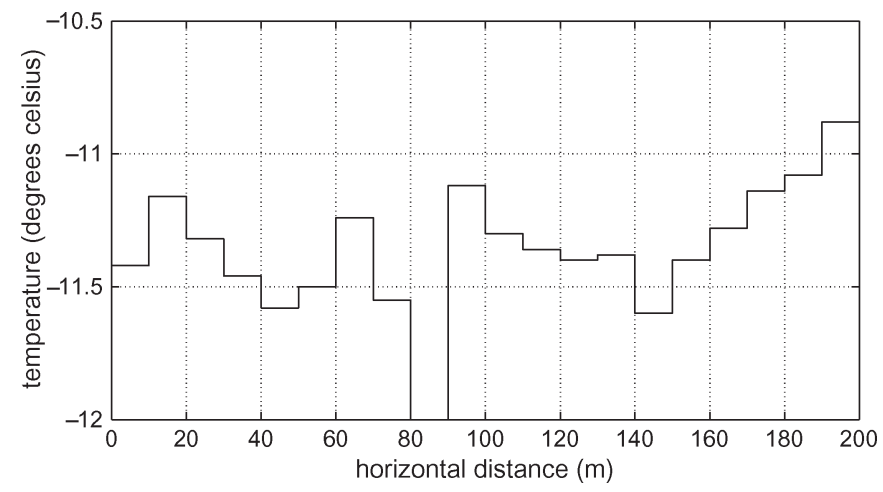

Fig. 15. In situ measured temperature profile over the line.

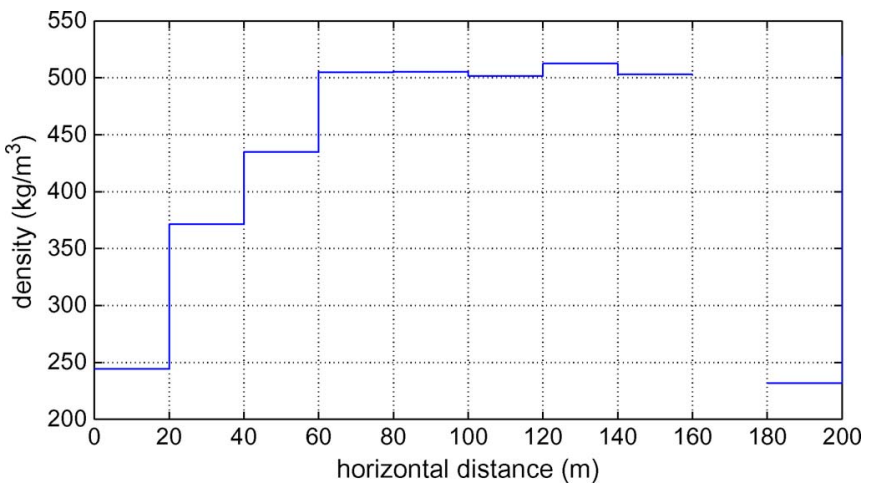

Fig. 16. In situ measured snow density profile over the line.

the similar locations of two sections where very little snow thickness is observed in the middle of the prominent snow mound present along the line are between 90, 110, and $125 \mathrm{~m}$. This could be explained by the presence of icy/hard surfaces of the wind-packed snow. The presence of these features can perhaps just be identified in Fig. 12 at times of 3 and 4 s. These significantly limit the penetration of the radar signal into the snow pack, hence the absence of a distinct second surface. It is likely that icy layers are the cause of the fading, as the data are collected over fast ice, where in situ measurements detected many hard and wind-packed surfaces. Overall, the direct correlation coefficients calculated at the two altitudes are 0.53 and 0.57 , respectively, which are statistically significant $(p \leq$ $0.0005)$. The differences between the results from the flights at different altitudes are very little, and this can be explained by the fact that the operating conditions of the radar change little, with the active area not changing substantially enough for a significant change in surface roughness characteristics. Additionally, it points to the fact that it is probable that the helicopter instability is the dominant contributor to the error.

Applying a five-point moving average filter to the radar data increases the correlation with the in situ data to 0.8 in both cases. Results from a linear regression analysis are shown in Fig. 17. The gradient of the regression could be expected to be 1.0 , and it is seen to deviate from this value. The main reason for this could be due to an incorrect selection of the mapping coefficient between range-bin values in the radar and the actual measured snow thickness values. However, if this coefficient is changed to force the gradient to be 1.0, the residual norm increases from 0.168 to 0.182 , possibly indicating that the 


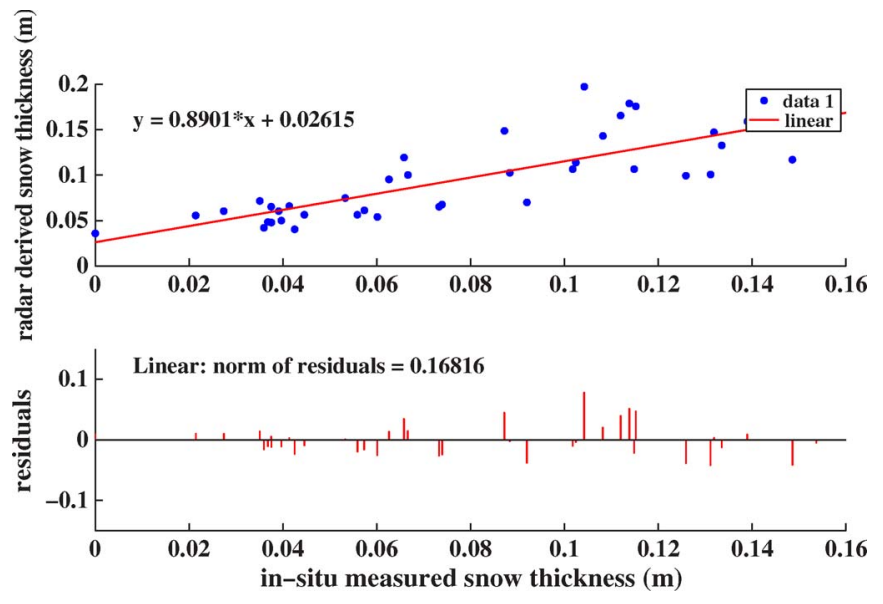

Fig. 17. Linear regression analysis of the radar and in situ data.

gradient deviation is a general bias in the radar toward smaller range-bin selection. This bias could be explained by the fact that the radar is unable to penetrate the frequently present icy or slush layer at the interface between the snow and ice, which a person with a ruler stick is unlikely to detect.

\section{A. Error Analysis}

The availability of in situ data for the flights allows for accuracy analysis of the radar system to be estimated, under the assumption that the correct (accurate) snow thickness was provided by the in situ data. The percentage error between the in situ and radar derived snow thicknesses (with the smoothing applied) was calculated over the transect length and averaged over the active area, and it was found to be approximately $\pm 17 \%$. It must be qualified that this error is the complete system error incorporating in itself all the possible sources of error in both the instrument and subsequent analysis, including the following: vibration, off-nadir attitude, residual nonlinearities, clutter, and processing error.

In the future, it would be desirable to perform an analysis into the sensitivity of the instrument to the main error sources; however, at this stage, it was not feasible. Additionally, an analysis into the nature of the averaging or integration performed by the radar of the air/snow and snow/ice signals over the active area footprint into a single value should be conducted in order to determine the main contributing features of the media.

It should also be mentioned that a correlation of 1.0 between the in situ and radar data, in fact, should not be aimed for and could, in practice, rarely be achieved. The reasons for this are that the radar's view of the world and a ruler measurement of snow thickness could not even theoretically be in one-to-one correspondence. The radar signal may be affected by an icy layer and increased wetness or salinity within the snow pack, which a human may not observe.

\section{Summary AND Discussion}

To date, while it is theoretically assumed possible, snow thickness extraction over sea ice in Antarctica from a heli-

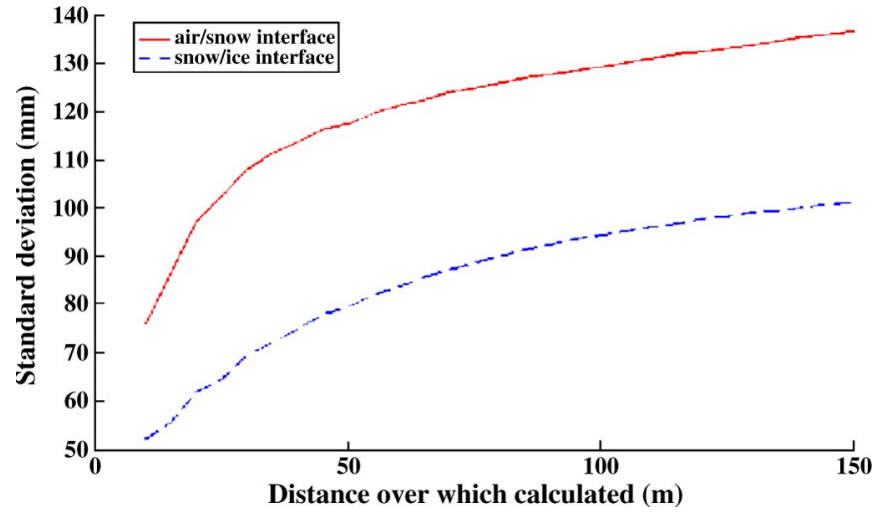

Fig. 18. Estimated roughness (as rms height) derived from the radar data for the air/snow and snow/ice interfaces.

copterborne platform has not been demonstrated. The reason for this is a product of two primary difficulties:

1) geophysical features of sea ice and its snow cover;

2) instrumentation difficulties.

The first problem captures the suite of difficulties presented by particular conditions of sea ice and its snow cover in the Antarctic where it is frequently wet, icy, rough, and relatively thin (order of tens of centimeters), hence requiring a small viewing aperture, high resolution, and high incident power. The second problem refers to the difficulties in obtaining a highresolution instrument and, then, the subsequent difficulties in validating helicopterborne data which are a highly unstable platform, particularly when aiming for centimeter-scale vertical resolution. Overcoming these difficulties, this paper has presented a step-by-step analysis of the complete radar system and a validation process of the radar and in situ derived snow thickness data, with a radar system of accuracy of $17 \%$.

Given the large beamwidth of the radar, coupled with the large bandwidth (for high vertical resolution), the necessary condition for unambiguous identification of the air/snow and snow/ice layers is presented. The condition is strongly sensitive to the surface roughness features; however, the laser data and simple approximation calculations for the backscattering coefficient demonstrate that, at least, over the site chosen for study, the condition is satisfied. However, extension to further areas, and particularly into the pack ice zone, where roughness is expected to be much greater, requires improvement of the instrument performance, namely, decreasing the antenna beamwidth.

An extension of the utilization of the FMCW radar data set is exploiting the fact that the radar receives returns simultaneously and independently from the air/snow and snow/ice interfaces. Hence, the relative roughness features of the snow cover and underlying sea ice can be extracted. This is not currently available in any other remote sensing data set and provides much needed insight into the hypothesized relationship between ice roughness and snow thickness, as well as further study into the AMSR-E snow thickness extraction algorithm, and its sensitivity to roughness. Fig. 18 shows the calculated relative estimates of the roughness as a function of increasing integration length, showing that the air/snow interface is rougher than that of the 
underlying ice, which is in agreement with the observations of this fast-ice area.

Future engineering work on the radar will be addressing the antenna design and mounts in order to increase their stability, as well as the linearity of the frequency modulation from 2 to $8 \mathrm{GHz}$, and increasing the number of chirps transmitted per second in order to improve the radar accuracy and precision of the coupled radar-helicopter system.

\section{ACKNOWLEDGMENT}

The authors would like to thank J. L. Lieser (Antarctic Climate and Ecosystems Cooperative Research Centre) and P. Jansen for collection and processing of the LiDAR data set and the kind release for this study.

\section{REFERENCES}

[1] S. Manabe and R. J. Stouffer, "Sensitivity of a global climate model to an increase of $\mathrm{CO}_{2}$ in the atmosphere," J. Geophys. Res., vol. 85, no. C10, pp. 5529-5554, Oct. 1980.

[2] W. M. Washington and C. L. Parkinson, An Introduction to ThreeDimensional Climate Modeling. Mill Valley, CA: Univ. Sci. Books, 2005.

[3] R. E. Brandt, S. G. Warren, A. P. Worby, and T. C. Grenfell, "Surface albedo of the Antarctic sea ice zone," J. Clim., vol. 18, no. 17, pp. 36063622, Sep. 2005.

[4] H. Eicken, H. Fischer, and P. Lemke, "Effects of the snow cover on Antarctic sea ice and potential modulation of its response to climate change," Ann. Glaciology, vol. 21, pp. 369-376, 1995.

[5] H. J. Zwally, D. Yi, R. Kwok, and Y. Zhao, "ICESat measurements of sea ice freeboard and estimates of sea ice thickness in the Weddell Sea," $J$. Geophys. Res., vol. 113, p. C02 S15, 2008.

[6] R. Kwok and G. F. Cunningham, "ICESat over Arctic sea ice: Estimation of snow depth and ice thickness," J. Geophys. Res., vol. 113, no. C8, p. C08 010, Aug. 2008.

[7] K. A. Giles, S. M. Laxon, and A. P. Worby, "Antarctic sea ice elevation from satellite radar altimetry," Geophys. Res. Lett., vol. 35, no. 3, p. L03 503, Feb. 2008.

[8] A. P. Worby, C. A. Geiger, M. J. Paget, M. L. Van Woert, S. F. Ackley, and T. L. DeLiberty, "Thickness distribution of Antarctic sea ice," J. Geophys. Res., vol. 113, p. C05 S92, May 2008.

[9] J. C. Comiso, D. J. Cavalieri, and T. Markus, "Sea ice concentration, ice temperature, and snow depth using AMSR-E data," IEEE Trans. Geosci. Remote Sens., vol. 41, no. 2, pp. 243-252, Feb. 2003.

[10] T. Markus and D. J. Cavalieri, "Snow depth distribution over sea ice in the southern ocean from satellite passive microwave data," Antarctic Sea Ice-Phys. Process., Interactions Variability, Antarctic Res. Ser., vol. 74, pp. 19-39, 1998.

[11] D. C. Powell, T. Markus, D. J. Cavalieri, A. Gasiewski, M. Klein, J. A. Maslanik, J. C. Stroeve, and M. Sturm, "Microwave signatures of snow on sea ice: Modeling," IEEE Trans. Geosci. Remote Sens., vol. 44, no. 11, pp. 3091-3102, Nov. 2006.

[12] A. P. Worby, T. Markus, A. D. Steer, V. I. Lytle, and R. A. Massom, "Evaluation of AMSR-E snow depth product over East Antarctic sea ice using in situ measurements and aerial photography," J. Geophys. Res., vol. 113, no. C5, p. C05 S94, May 2008.

[13] R. Massom, A. P. Worby, V. I. Lytle, T. Markus, D. Yi, K. Tateyama, H. Enomoto, A. Steer, and J. Zwally, "Early springtime snow cover on East Antarctic sea ice, ARISE 2003: Variability and satellite validation," Ann. Glaciology, vol. 44, no. 1, pp. 288-296, 2003.

[14] C. J. Leuschen, R. N. Swift, J. C. Comiso, R. K. Raney, R. D. Chapman, W. B. Krabill, and J. G. Sonntag, "Combination of laser and radar altimeter height measurements to estimate snow depth during the 2004 Antarctic AMSR-E Sea Ice field campaign," J. Geophys. Res., vol. 113, no. C4, p. C04 S90, 2008.

[15] H. P. Marshall and G. Koh, "FMCW radars for snow research," Cold Regions Sci. Technol., vol. 52, no. 2, pp. 118-131, Apr. 2008.

[16] G. Koh, N. E. Yankielun, and A. I. Baptista, "Snow cover characterisation using multiband FMCW radars," Hydrol. Process., vol. 10, no. 12, pp. 1609-1617, Dec. 1996.
[17] P. Kanagaratnam, T. Markus, V. I. Lytle, B. Heavey, P. Jansen, G. Prescott, and S. P. Gogineni, "Ultra-wideband radar measurements of thickness of snow over sea ice," Trans. Geosci. Remote Sens., vol. 45, no. 9, pp. 27152724, Sep. 2007.

[18] J. Holmgren, M. Sturm, N. E. Yankielun, and G. Koh, "Extensive measurements of snow depth using FM-CW radar," Cold Regions Sci. Technol., vol. 27, no. 1, pp. 17-30, Feb. 1998.

[19] T. Rink, P. Kanagaratnam, D. Braaten, T. Akins, and S. P. Gogineni, "A wideband radar for mapping near-surface layers in snow," in Proc. IGARSS, Denver, CO, 2006, pp. 3655-3657.

[20] H. P. Marshall, K. Birkeland, K. Elder, and T. Meiners, "Helicopter-based microwave radar measurements in alpine terrain," in Proc. Int. Snow Sci. Workshop, 2008.

[21] N. E. Yankielun, "An airborne millimeter-wave FM-CW radar for thickness profiling of freshwater ice," CRREL1992.

[22] R. Willyard, "Airborne Radar for Measuring Snow Thickness Over Sea Ice," M.S. thesis, Univ. Kansas, Lawrence, KS, 2006.

[23] G. M. Brooker, "Understanding millimeter wave FMCW radars," in Proc. ICST, 2005, pp. 152-157.

[24] S. P. Gogineni and G. E. Prescott, "Validation of AMSR-E snow depth on sea ice retrievals using an airborne pulse radar," Radar Syst. Remote Sens. Lab., 2001.

[25] F. T. Ulaby, R. K. Moore, and A. K. Fung, Microwave remote sensing active and passive, vol. II. Dedham, MA: Artech House, 1986

[26] A. D. Frolov and Y. Y. Macheret, "On dielectric properties of dry and wet snow," Hydrol. Process., vol. 13, no. 12/13, pp. 1755-1760, Sep. 1999.

[27] M. T. Hallikainen, F. T. Ulaby, and M. Abdelrazik, "Dielectric properties of snow in the 3 to $37 \mathrm{GHz}$ range," IEEE Trans. Antennas Propag., vol. AP-34, no. 11, pp. 1329-1340, Nov. 1986.

[28] M. I. Skolnik, Radar Handbook. New York: McGraw-Hill, 1970.

[29] F. D. Carsey, Microwave Remote Sensing of Sea Ice. Washington, DC: Amer. Geophys. Union, 1992.

[30] R. C. Willatt, K. A. Giles, S. W. Laxon, L. Stone-Drake, and A. P. Worby, "Field investigations of Ku-band radar penetration into snow cover on Antarctic sea ice," IEEE Trans Geosci. Remote Sens., vol. 48, no. 1, pp. 365-372, Jan. 2010.

[31] S. V. Nghiem, R. Kwok, S. H. Yueh, and M. R. Drinkwater, "Polarimetric signatures of sea ice. 1. Theoretical model," J. Geophys. Rese. , vol. 100, no. C7, pp. 13 665-13 680, Aug. 1995.

[32] D. G. Barber, A. K. Fung, T. C. Grenfell, S. V. Nghiem, R. G. Onstott, V. Lytle, D. K. Perovich, and A. J. Gow, "The role of snow on microwave emission and scattering over first-year sea ice," IEEE Trans. Geosci. Remote Sens., vol. 36, no. 5, pp. 1750-1764, Sep. 1998.

[33] H. Griffiths, "The effect of phase and amplitude errors in FM radar," in Proc. Inst. Elect. Eng.-Colloq. High Time-Bandwidth Product Waveforms Radar Sonar, 1991, pp. 9/1-9/5.

[34] A. Meta, P. Hoogeboom, and L. Ligthart, "Signal processing for FMCW SAR," IEEE Trans. Geosci. Remote Sens., vol. 45, no. 11, pp. 3519-3532, Nov. 2007.

[35] M. P. Vossiek, P. Heide, M. Nalezinski, and V. Magori, "Novel FMCW radar system concept with adaptive compensation of phase errors," in Proc. EuMC, Prague, Czech Republic, 1996, pp. 135-139.

[36] S. P. Gogineni, C. Leuschen, A. Patel, F. Rodriguez-Morales, and T. Satyanarayana, "Validation of AMSR snow depth on sea ice retrievals using an airborne pulse radar," Center for Remote Sensing of Ice Sheets, 2009.

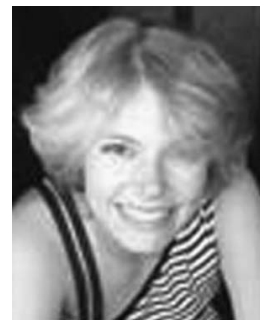

Natalia Galin received the B.Eng. degree in electrical engineering from The University of New South Wales, Sydney, Australia, in 2006. Her Ph.D. work was aimed at measuring snow thickness on sea ice over Antarctica from a helicopterborne frequency modulated continuous wave radar.

She is currently a Postdoctoral Research Fellow with the Centre for Polar Observation and Modelling, University College London, London, U.K., where she is working on CryoSat-2 data, measuring changes in ice-sheet mass balance. 


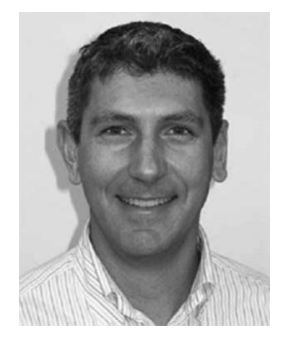

Anthony Worby received the B.Sc.(Hons.) degree in oceanography and meteorology from the Flinders University of South Australia, Adelaide, Australia, and the Ph.D. degree from the University of Tasmania, Hobart, Australia.

$\mathrm{He}$ is currently the Program Leader for Climate Processes and Change theme with the Australian Antarctic Division, Kingston, Australia. His particular interest includes the role of sea ice in the climate system and the thickness distribution of sea ice and snow cover around Antarctica.

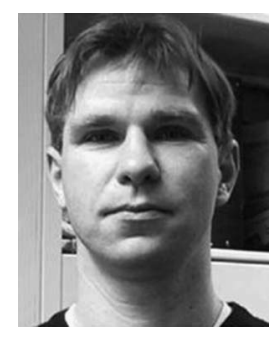

Thorsten Markus received the M.S. and Ph.D. degrees in physics from the University of Bremen, Bremen, Germany, in 1992 and 1995, respectively.

$\mathrm{He}$ is currently the Head of the Cryospheric Sciences Branch, Hydrospheric and Biospheric Sciences Laboratory, Goddard Space Flight Center, National Aeronautics and Space Administration, Greenbelt, MD. His research interests include satellite and airborne remote sensing of cryospheric, oceanic, and atmospheric processes. He is the Project Scientist for ICESat-2.

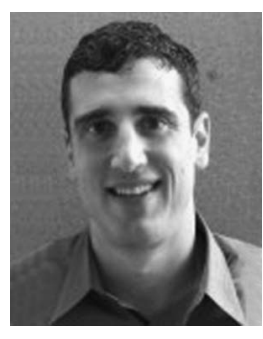

Carl Leuschen received the B.S. and M.S. degrees in electrical engineering from The University of Kansas, Lawrence, in 1995 and 1997, respectively.

Since 1995, he has been with the Radar Systems and Remote Sensing Laboratory, University of Kansas, where he was a Graduate Teaching Assistant for the Sensor Design Laboratory. His research interests include ground-penetrating radar, numerical electromagnetics, and signal processing with emphasis on wave migration and synthetic aperture radar.

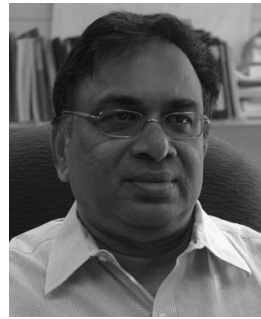

Prasad Gogineni (M'84-SM'92-F'99) received the $\mathrm{Ph} . \mathrm{D}$. degree in electrical engineering from the University of Kansas, Lawrence, in 1984.

He is currently a Deane Ackers Distinguished Professor with the Department of Electrical Engineering and Computer Science, University of Kansas, Lawrence, where he is also currently the Director of the National Science Foundation Science and Technology Center for Remote Sensing of Ice Sheets. He has been involved with radar sounding and imaging of ice sheets for more than 15 years and contributed to the first successful demonstration of synthetic aperture radar imaging of the ice bed through more than 3-km-thick ice. 